\title{
Novel mutation in carnitine palmitoyltransferase 1A detected through newborn screening for a presymptomatic case in China囚A case report and literature review
}

\section{Haining Fang}

Maternal and Child health hospital of hubei province

Yi Gan

Maternal and Child Health Hospital of Hubei Province

Fei Yu ( $\nabla$ yf123456hbsfy@163.com )

Huazhong University of Science and Technology

\section{Case report}

Keywords: Carnitine palmitoyltransferase 1A deficiency, Tandem mass spectrometry, Gene mutation, Newborn screen, Case report

Posted Date: November 9th, 2020

DOI: https://doi.org/10.21203/rs.3.rs-99431/v1

License: (c) (1) This work is licensed under a Creative Commons Attribution 4.0 International License. Read Full License

Version of Record: A version of this preprint was published at Italian Journal of Pediatrics on July 7th, 2021. See the published version at https://doi.org/10.1186/s13052-021-01094-5. 


\section{Abstract}

Background囚Carnitine palmitoyltransferase 1A (CPT1A) deficiency is a rare mitochondrial fatty acid oxidation (FAO) disorder that results in hypoketotic hypoglycemia and hepatic encephalopathy. It is caused by mutation in CPT1A. To date, only two symptomatic cases of CPT1A deficiency have been reported in China.

Case presentation: A newborn male, without any disease-related clinical manifestations, was diagnosed with CPT1A deficiency through newborn screening. Increased free carnitine levels and a significantly increased $\mathrm{CO} /(\mathrm{C} 16+\mathrm{C} 18)$ ratio were detected at 3 days of age, and subsequently, mutations in CPT1A were found by gene sequence analysis. The patient was advised a low-fat, high-protein diet and followed up regularly. During three-years of follow-up since, the patient showed normal growth velocity and developmental milestones. Whole-exome sequencing identified two mutations, c.2201T >C (p.F734S) and c.1318G >A (p.A440T), in the patient. The c.2201T >C mutation, which has been reported previously, was inherited from his father, while the $\mathrm{c} .1318 \mathrm{G}>\mathrm{A}$, a novel mutation, was inherited from his mother. The amino acid residues encoded by original sequences are highly conserved across different species. These mutations slightly altered the three-dimensional structure of the protein, as analyzed by molecular modeling, suggesting that they may be pathogenic.

Conclusion: This is the first case of CPT1A deficiency detected through newborn screening based on diagnostic levels of free carnitine, in China. We identified two missense mutations, c.2201T $>C$ and novel c. $1318 \mathrm{G}>\mathrm{A}$, in the patient. Our findings have expanded the gene spectrum of this rare condition and provided a basis for family genetic counseling and prenatal diagnosis.

\section{Background}

Carnitine palmitoyltransferase 1A (CPT1A, EC\# 2.3.1.21) deficiency is a rare autosomal recessive inherited disorder of the carnitine cycle (MIM \#255120). ${ }^{[1]}$ It is caused by mutations in the gene coding CPT1A, which is located in chromosome 11q13.3(Fig. 1A). ${ }^{[2]}$ This enzyme is essential for transport of long-chain fatty acyl-CoA esters into the mitochondria for subsequent beta-oxidation. Loss of CPT-1A activity diminishes the intra-mitochondrial substrate levels for fatty acid beta-oxidation, thereby impairing energy generation. ${ }^{[1]}$ Therefore, patients with CPT1A deficiency usually present hypoketotic hypoglycemia and hepatic encephalopathy after long periods of fasting. As reported, the onset usually occurs within 18 months from birth, following various symptoms including hypoketotic hypoglycemia, lethargy and seizures. ${ }^{[3]}$ In this report, we present the first presymptomatic case of CPT1A deficiency detected through newborn screening in China and a novel mutation have been found. Moreover, we identified a novel mutation associated with this disorder.

\section{Case Presentation}

Clinical History 
A male child was born of a normal pregnancy and natural delivery in our hospital and is the only child of his parents. His gestational age was 39 weeks, Apgar score 10/1, 10/5, 10/10, birth weight 3,500 g. When the boy was 44 days old, a newborn screening sample obtained at 3 days of age showed increased blood free carnitine(C0) level of $128.1 \mathrm{mmol} / \mathrm{L}(\mathrm{ref}<50 \mathrm{mmol} / \mathrm{L}$ ) and increased $\mathrm{C} /(\mathrm{C} 16+\mathrm{C} 18)$ ratio of 512.4 (ref < 42). These abnormal results were confirmed by testing again on day 51 after birth, the results showed $65.86 \mathrm{mmol} / \mathrm{L}$ free carnitine ( $\mathrm{ref}<100 \mathrm{mmol} / \mathrm{L}$ ) and a significantly increased $\mathrm{C} 0 /(\mathrm{C} 16+\mathrm{C} 18)$ ratio of 1423.97 ( $r$ ef $<100$ ), which were consistent with CPT1A deficiency. ${ }^{[3]}$ Based on these results, the boy was thoroughly examined. Cranial MRI showed no significant abnormalities echocardiogram was normal. Laboratory findings for blood sample were: $\mathrm{pH}, 7.4$; base excess, $4.9 \mathrm{mmol} / \mathrm{L}$ (ref $4.0-$ $2.0 \mathrm{mmol} / \mathrm{L}$ ); bicarbonate, $18.4 \mathrm{mmol} / \mathrm{L}$ (ref $21.8-26.2 \mathrm{mmol} / \mathrm{L}$ ); ammonium, $29.2 \mathrm{mmol} / \mathrm{L}$ ( ref < $47 \mathrm{mmol} / \mathrm{L}$ ); lactate, $2.9 \mathrm{mmol} / \mathrm{L}$ (ref 0.5-2.2 mmol/L); thrombocytes $333 \times 10^{9} / \mathrm{L}$ (ref 160-360 10\%/L); hemoglobin, $111 \mathrm{~g} / \mathrm{L}$ (ref 110-160 g/L); alkaline phosphatase, $306 \mathrm{IU} / \mathrm{L}$ (ref 55-425 IU/L); alanine aminotransferase $38.7 \mathrm{IU} / \mathrm{L}$ (ref 5-50 IU/L); bilirubin, $52.2 \mu \mathrm{mol} / \mathrm{L}$ (ref 0-24 $\mu \mathrm{mol} / \mathrm{L}$ ),;plasma glucose, $4.6 \mathrm{mmol} / \mathrm{L}$ (ref $3.3-5.5 \mathrm{mmol} / \mathrm{L}$ ). These blood tests were repeated after 3 days and the results were normalized after treatment. The patient was discharged when the urine level of amino acids and organic acids became normal. The diagnosis of CPT1A deficiency was considered and confirmed by gene sequencing.

The patient was advised a low-fat, high-protein diet and followed-up regularly. On earlier occasions when he fell sick, hypoglycemia was prevented by early intervention with glucose infusion.

Every three months, the patient was examined by a specialist to evaluate if he suffered any neurologic damage due to possible episodes of hypoketotic hypoglycemia that are associated with CPT1A deficiency. There were no motor retardation and hypotonia. At 12 months of age, the boy could walk and talk. During the 3 years of follow-up since, his psychomotor development has been appropriate for his age.

Molecular Genetic Findings

CPT1A (Ensemble gene: ENST00000110090) was sequenced for the patient after obtaining written informed consent of his parents. The results showed two mutations: c.2201T > C (p.F734S) and c.1318G $>A$ (p.A440T) in exons 18 and 11, respectively. Then family screening of these mutations for patient's parents was performed. Results showed that the c.2201T >C mutation was transmitted from his father, while c.1318G > A mutation was transmitted from his mother (Fig. 1B, C-H). These variations were not listed in the SNP database(http://www.ncbi.nlm.nih.gov/projects/SNP/) $\square$ Human Gene Mutation Database Professional(http://www.hgmd.cf.ac.uk/ac/index.php). However, c.2201T >C has been reported once in one case of CPT1A deficiency in China, ${ }^{[4]}$ while $\mathrm{C} .1318 \mathrm{G}>\mathrm{A}$ has not been previously reported. According to PolyPhen2 (http://genetics.bwh.harvard.edu/pph2/), the c.2201T >C mutation was predicted to be "probably damaging" (score, 0.995 ) and c.1318G > A was predicted to be "possibly damaging" (score, 0.875 ), suggesting that both mutations may cause disease. The sequencing data revealed that both the mutations detected in our patient were missense mutations causing p.F734S and 
p.A440T replacement. Further, we conducted molecular modeling to predict the effect of these mutations on the protein structure of CPT1A (Fig. 2). We found that replacement of Thr440 with Ala440 results in an additional hydrogen bond between Thr440-MET436, and replacement of Ser734 with Phe734 results in the loss of hydrophobic bond force between Ser734-Phe549. As hydrogen and hydrophobic bond play an important role in maintaining protein spatial conformation and stability, these subtle changes in spatial structure may affect protein function. These data suggest that the mutation causing these substitutions may not be polymorphisms, but disease-causing mutations.

\section{Discussion And Conclusion}

CPT1A deficiency is a rare metabolic disease that affects fatty acid oxidation (FAO), and in the majority of cases, patients are diagnosed only after the appearance of clinic symptoms. Most patients present these symptoms by the age of 2 years with hypoketotic hypoglycemia induced by fasting or illness. ${ }^{[5]}$ This is usually accompanied by liver dysfunction; transient lipemia and renal tubular acidosis may also be present. ${ }^{[1]}$ As our patient underwent the newborn screening at the age of 3 days, indicators of CPT1A deficiency, namely, increased free carnitine and a significantly increased $\mathrm{C} 0 /(\mathrm{C} 16+\mathrm{C} 18)$ ratio, were detected early. The diagnosis of CPT1A deficiency was confirmed by gene sequence analysis. Dietetic management and avoidance of prolonged fasting were recommended to improve the patient's clinical outcome. ${ }^{[5]}$ Therefore, our patient developed normally, without severe metabolic crisis, till date.

Analysis of $C P T 1 A$ is necessary for accurate diagnosis. So far, more than 30 mutations in CPT1A, responsible for the CPT1A deficiency, have been identified. ${ }^{[6]}$ Our patient carried two missense mutations c.2201T > C (p.F734S), previously reported in one Chinese patient, ${ }^{[4]}$ and c.1318G >A (p.A440T), a novel mutation. The encoded amino are highly conserved across species. The glycine residue at 734 and 440 in CPT1A is highly conserved in bovine, chicken, chimpanzee, goat, horse, pig, rat, and macaque(Fig. 1I), suggesting that these loci play key roles in CPT1A normal function. According to prediction software analysis these mutations do not appear to be polymorphisms,but are more likely to be disease-causing mutations. As p.F734S mutation was only reported in a Chinese patient with heterozygous gene mutation, it may be a unique to Chinese lineage.

As we have listed the CPT1A mutations reported so far, based on the geographic region in Table 1. Most mutations seem to be unique or restricted to only a few pedigrees, except c.2129G >A and c. $1436 \mathrm{C} \square \mathrm{T}$. [2] While c.2129G > A (p.G710E), a homozygous mutation associated with disease severity, is mainly found in Alaskan and Hutterite populations in the USA. ${ }^{[7]}$ c. $1436 \mathrm{C}>\mathrm{T}$ mutation (p.P479L) was more common in northern Canada, Greenland, Colombia, as well as the native Alaskan population. ${ }^{\left[{ }^{[8}\right.}$ The incidence of this disorder appears to be quite low in other regions. To date, only two cases with CPT1A deficiency have been reported in China, ${ }^{[4,9]}$ and both were diagnosed after the patients ( $>1$ year old) exhibited symptoms of hypoglycemia followed by diarrhea and fever. Moreover, there is almost complete genetic heterogeneity of disease-causing CPT1A variations with each affected family demonstrating novel variation(s) of 
CPT1A. ${ }^{[1]}$ Therefore, analysis of the entire CPT1A is required to confirm an abnormal newborn screen and the disease-causing nature of the abnormal genotypes needs to be carefully interpreted. ${ }^{[10,11]}$

Table 1

Reported CPT1A Pathogenic Variants

\begin{tabular}{|c|c|c|c|}
\hline Country & Variants & case & reference \\
\hline Alaska & c. $1436 \mathrm{C}>\mathrm{T}$ & * & [10] \\
\hline China & c.281 + 1G > A/IVS2_IVS5del; c.1787T > C/c.2201T >C & 2 & {$[4,9]$} \\
\hline Korean & c.837_838ins(T)/c.947G >A & 1 & [5] \\
\hline Denmark & c. $167 \mathrm{C}>\mathrm{T}$ & 1 & [11] \\
\hline Finland & c. $1364 A>C ;$ c. $1364 A>C / c .1493 A>C ; c .1463 C>T$ & 6 & [13] \\
\hline \multirow[t]{2}{*}{ Japan } & c. $1339 \mathrm{C}>\mathrm{T} / \mathrm{c} .2156 \mathrm{G}>\mathrm{A} ; \mathrm{c} .96 \mathrm{~T}>\mathrm{G} / \mathrm{c} .1079 \mathrm{~A}>\mathrm{G}$ & 4 & {$[6,14,15]$} \\
\hline & 2027-2028 + 2del;c.1425G > A/c.1494T > G & & \\
\hline Netherlands & c. $1737 \mathrm{C}>\mathrm{A} ; \mathrm{c} .478 \mathrm{C}>\mathrm{T} ;$ c c.1600delC; c. $1361 \mathrm{~A}>\mathrm{G}$ & 4 & {$[16,17]$} \\
\hline American & $\begin{array}{l}\text { c. } 1393 \mathrm{G}>\mathrm{T} ; \mathrm{c} .1027 \mathrm{~T}>\mathrm{C} ; \mathrm{c} .478 \mathrm{C}>\mathrm{T} ; \mathrm{c} .946 \mathrm{C}>\mathrm{G} / \mathrm{?} ; \mathrm{c} .986 \mathrm{C}> \\
\mathrm{T} ; \mathrm{c} .1163+1 \mathrm{G}>\mathrm{A} ; \mathrm{c} .823 \mathrm{G}>\mathrm{A} / \mathrm{c} .912 \mathrm{C}>\mathrm{G} ; \mathrm{c} .367 \mathrm{C}>\mathrm{T} ; \mathrm{c} .2129 \mathrm{G}>\mathrm{A}^{\#}\end{array}$ & $8+\#$ & {$[1,18-20]$} \\
\hline France & c. 298 C > T; C.1241C > T/1493A > G; IVS14 + 3 kb; c. $1876-1 G>A$ & 4 & [21] \\
\hline Indian & c. $1069 \mathrm{C}>\mathrm{T} / \mathrm{c} .1451 \mathrm{~T}>\mathrm{C}$ & 1 & [20] \\
\hline \multicolumn{4}{|c|}{$\begin{array}{l}\text { Those variants followed the standard naming conventions of the Human Genome Variation } \\
\text { Society(http://varnomen.hgvs.org/). }\end{array}$} \\
\hline \multicolumn{4}{|c|}{ *Inuit mutation } \\
\hline \#Hutterite $\mathrm{m}$ & tion & & \\
\hline
\end{tabular}

Newborn screening programs, which allow early detection of metabolic markers in dried whole blood spots when the newborn is catabolic, are therefore very important. ${ }^{[3]}$ However, screening for CPT1A deficiency is not included in the newborn screening program in every province in China. Since 2016, Central China (Hubei Province) newborn screening program has included screening for disorders of fatty acid oxidation using tandem mass spectrometry (MS/MS), and more than 120,000 newborn children have been tested so far. The MS/MS is used to detect elevated free carnitine to $\mathrm{C} 16+\mathrm{C} 18$ ratio, which is characteristic of $\mathrm{CPT} 1 \mathrm{~A}$ patient ${ }^{[3]}$. According to the data from newborn screening programs in Australia, Germany, and the USA the incidence of CPT1A deficiency may be as low as $1: 750,000$ to $1: 2,000,000 .{ }^{[12]}$ The present case is the first presymptomatic CPT1A deficiency case detected through newborn screening in China. A previous reports has indicated that following a strict dietary regimen allows the CPT1A- 
deficient infant to lead a healthy life with normal growth and development. ${ }^{[3]}$ Consistent with this reports, our patient was diagnosed at an early age, received timely intervention, and showed a normal growth trend. Therefore, the newborn metabolic screen is important for early diagnosis and treatment.

Considering the simplicity of this method, it can be implemented across the country. Moreover, in the present cases, genetic counseling was recommended for the parents, should they wish to have another baby.

In conclusion, we used neonatal screening using MS/MS to diagnose CPT1A deficiency in presymptomatic newborn. The early diagnosis and diet management improved the prognosis in our patient. Further, we identified a novel mutation $\mathrm{c} .1318 \mathrm{G}>\mathrm{A}$ in $C P T 1 A$, which is probably disease-causing. Thus, our finding has expanded the gene spectrum of this rare condition and provided a basis for genetic counseling of the family and prenatal diagnosis.

\section{Abbreviations}

CPT1A: Carnitine palmitoyltransferase 1A; FAO:fatty acid oxidation; MS/MS:tandem mass spectrometry

\section{Declarations}

\section{Ethics approval and consent to participant}

This study was approved by the Ethics Committee of Maternal and Child Health Hospital of Hubei Province. All participants gave their written informed consent to take part in the present study.

\section{Consent for publication}

This family have given their written consents for the case report to be published.

\section{Availability of data materials}

The datasets used and analyzed during the current study are available from the corresponding author on the reasonable request.

\section{Competing interests}

The authors declare that they have no competing interest.

\section{Funding}

This research was supported by no fund.

\section{Authors' contributions}


YG wrote the manuscript and researched data. HF researched data and contributed to the manuscript. FY instructed and supervised this study. All authors read and approved the final manuscript.

\section{Acknowledgements}

We thank the patient and his family for their contribution.

\section{References}

1. Bennett MJ, Boriack RL, Narayan S, Rutledge SL, Raff ML. Novel mutations in CPT 1A define molecular heterogeneity of hepatic carnitine palmitoyltransferase I deficiency. Mol Genet Metab. 2004;82(1):59-63. DOI:10.1016/j.ymgme.2004.02.004.

2. University of Washington, Seattle. Bennett MJ, Santani AB. Carnitine palmitoyltransferase1A deficiency. In: Pagon RA, Adam MP, Ardinger HH, Wallace SE, Amemiya A, Bean LJH et al, editors. GeneReviews(R). Seattle: Seattle University of Washington, 2005. https://www.ncbi.nlm.nih.gov/books/NBK1527/.

3. Dykema DM. Carnitine palmitoyltransferase-1A deficiency: a look at classic and arctic variants. Adv Neonatal Care. 2012. 12(1): 23 - 7. DOI: 10.1097/ANC.0b013e318242df6d.

4. Dong Cui Y, Shen HD, et al. Clinical features and genetic analysis of a case with carnitine palmitoyltransferase 1A deficiency. Chinese Journal of Medical Genetics.2017.34(2):228-231.(in chinese).DOI: 10.3760/cma.j.issn.1003-9406.2017.02.017.

5. Lee BH, Kim YM, Kim JH, et al. Atypical manifestation of carnitine palmitoyltransferase $1 \mathrm{~A}$ deficiency: hepatosplenomegaly and nephromegaly. J Pediatr Gastroenterol Nutr. 2015;60(3):e1922. DOI:10.1097/MPG.0b013e3182a95a42.

6. Tsuburaya R, Sakamoto $\mathrm{O}$, Arai $\mathrm{N}$, et al. Molecular analysis of a presymptomatic case of carnitine palmitoyl transferase I (CPT I) deficiency detected by tandem mass spectrometry newborn screening in Japan. Brain Dev. 2010;32(5):409-11. DOI:10.1016/j.braindev.2009.03.004.

7. Prip-Buus $C$, Thuillier $L$, Abadi N, et al. Molecular and enzymatic characterization of a unique carnitine palmitoyltransferase $1 \mathrm{~A}$ mutation in the Hutterite community. Mol Genet Metab. 2001;73(1):46-54. DOI:10.1006/mgme.2001.3176.

8. Park JY, Narayan SB, Bennett MJ. Molecular assay for detection of the common carnitine palmitoyltransferase 1A 1436(C > T) mutation. Clin Chem Lab Med. 2006;44(9):1090-1. DOI:10.1515/CCLM.2006.196.

9. Zhang $\mathrm{H}$, Yuan $\mathrm{Y}$, Tang L, et al. Clinical Characteristics of One Case of Carnitine Palmitoyltransferase 1 A Deficiency and Analysis of CPT1A Gene Mutation. Journal of Pediatric Pharmacy. 2019. (11): 23-7. (in chinese).DOI:10.13407/j.cnki.jpp.1672-108X.2019.11.007.

10. Gessner BD, Gillingham MB, Johnson MA, et al. Prevalence and distribution of the c.1436C $\rightarrow T$ sequence variant of carnitine palmitoyltransferase $1 \mathrm{~A}$ among Alaska Native infants. J Pediatr. 2011;158(1):124-9. DOI:10.1016/j.jpeds.2010.07.031. 
11. Borch L, Lund AM, Wibrand F, et al. Normal Levels of Plasma Free Carnitine and Acylcarnitines in Follow-Up Samples from a Presymptomatic Case of Carnitine Palmitoyl Transferase 1 (CPT1) Deficiency Detected Through Newborn Screening in Denmark. JIMD Rep. 2012;3:11-5. DOI:10.1007/8904_2011_35.

12. Lindner M, Hoffmann GF, Matern D. Newborn screening for disorders of fatty-acid oxidation: experience and recommendations from an expert meeting. J Inherit Metab Dis. 2010;33(5):521-6. DOI:10.1007/s10545-010-9076-8.

13. Roomets E, Polinati PP, Euro L, Eskelin PM, Paganus A, Tyni T. Carrier frequency of a common mutation of carnitine palmitoyltransferase $1 \mathrm{~A}$ deficiency and long-term follow-up in Finland. J Pediatr. 2012;160(3):473-9.e1. DOI:10.1016/j.jpeds.2011.08.032.

14. Ogawa $E$, Kanazawa $M$, Yamamoto $S$, et al. Expression analysis of two mutations in carnitine palmitoyltransferase IA deficiency. J Hum Genet. 2002;47(7):342-7. DOI:10.1007/s100380200047.

15. Yamamoto S, Kanazawa M, Ogawa A, Takayangi M, Ohtake A, Kohno Y, Molecular analysis of hepatic carnitine palmitoyltransferase I deficiency: cDNA and genomic DNA analyses of infants presenting with Reye-like illness, J. Inherit. Metab. Dis. 23 (Suppl. 1) (2000) 229 (Abstract). https://doi.org/10.1023/A:1017326813602.

16. Korman SH, Waterham HR, Gutman A, Jakobs C, Wanders RJ. Novel metabolic and molecular findings in hepatic carnitine palmitoyltransferase I deficiency. Mol Genet Metab. 2005;86(3):337-43. DOI:10.1016/j.ymgme.2005.07.022.

17. IJlst L, Mandel H, Oostheim W, Ruiter JP, Gutman A, Wanders RJ. Molecular basis of hepatic carnitine palmitoyltransferase I deficiency. J Clin Invest. 1998;102(3):527-31. DOI:10.1172/JCI2927.

18. Stoler JM, Sabry MA. C. Hanley et al. Successful long-term treatment of hepatic carnitine palmitoyltransferase I deficiency and a novel mutation. J Inherit Metab Dis. 2004;27:679. https://doi.org/10.1023/B:BOLI.0000042979.42120.55.

19. Dowsett L, Lulis L, Ficicioglu C, Cuddapah S. Utility of Genetic Testing for Confirmation of Abnormal Newborn Screening in Disorders of Long-Chain Fatty Acids: A Missed Case of Carnitine Palmitoyltransferase 1A (CPT1A) Deficiency. Int J Neonatal Screen. 2017. 3(2). DOI:10.3390/ijns3020010.

20. Brown NF, Mullur RS, Subramanian I, et al. Molecular characterization of L-CPT I deficiency in six patients: insights into function of the native enzyme. J Lipid Res. 2001;42(7):1134-42. http://www.jl.org/content/42/7/1134.long.

21. Gobin S, Bonnefont JP, Prip-Buus C, et al. Organization of the human liver carnitine palmitoyltransferase 1 gene (CPT1A) and identification of novel mutations in hypoketotic hypoglycaemia. Hum Genet. 2002;111(2):179-89. DOI:10.1007/s00439-002-0752-0.

\section{Figures}




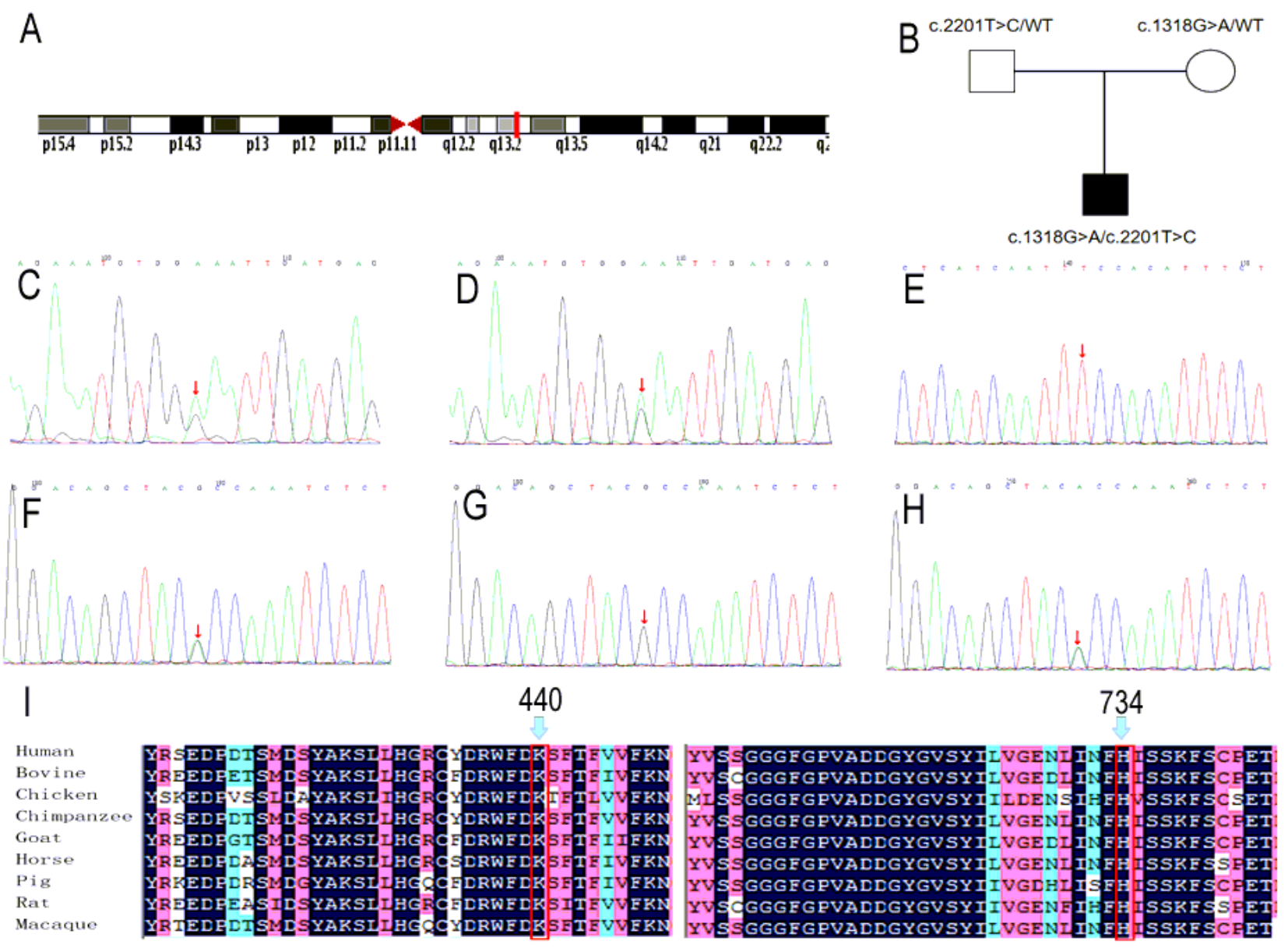

Figure 1

(A) Pedigree chart of the family. (B) CPT1A Gene in genomic location:11q13.3 (C-H) Consequence of DNA analysis: (C) The patient carrying 2201T $>C$ mutation. (D) His father carrying 2201T $>C$ mutation. (E) His mother: normal. (F) The patient carrying 1318T>C mutation. $(G)$ His father: normal. $(H)$ His mother carrying 1318T $>C$ mutation. (I) Multiple species alignment analysis showed the high evolutionary conservation of amino acid sequence at the mutation site. 


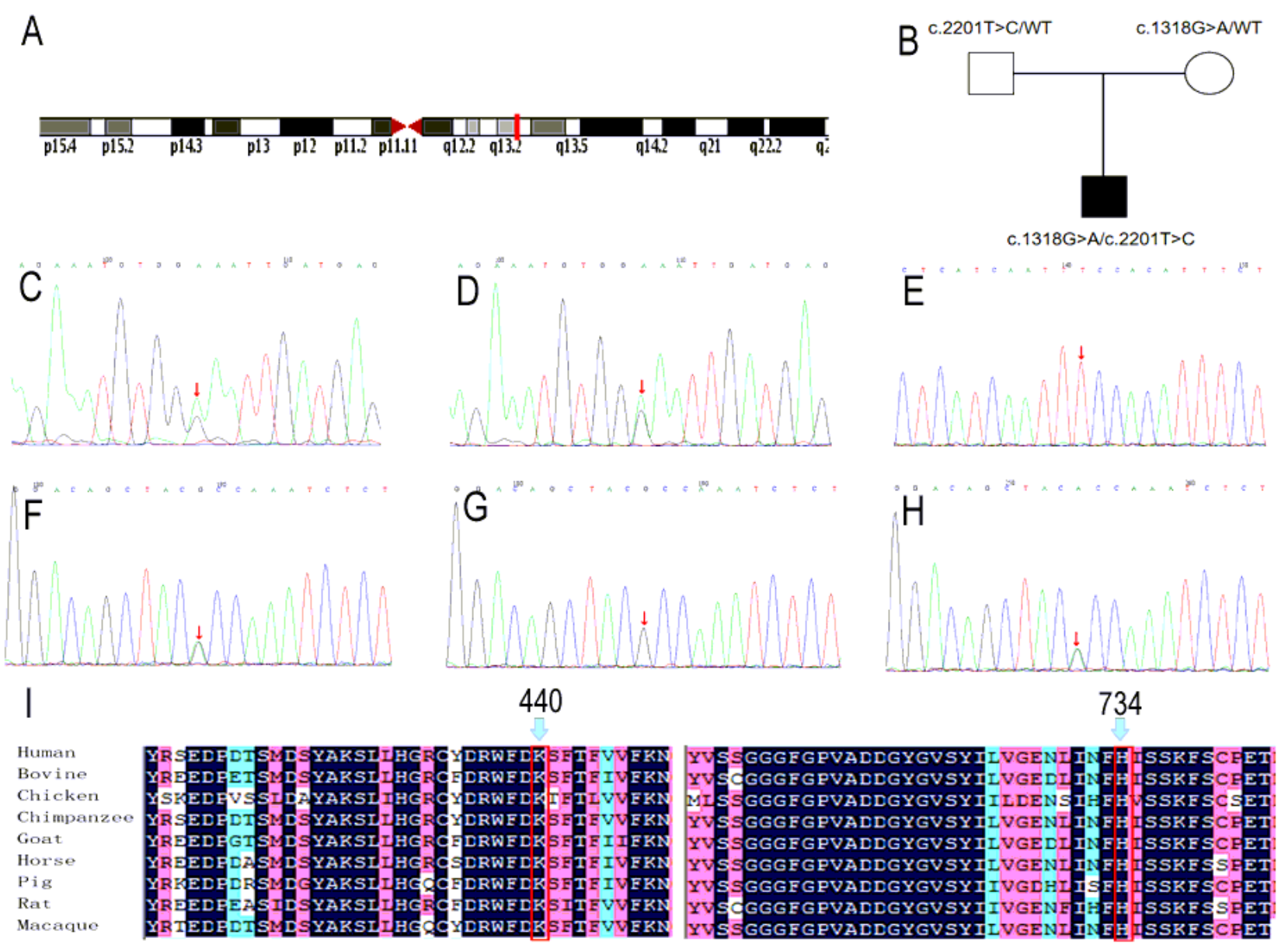

Figure 1

(A) Pedigree chart of the family. (B) CPT1A Gene in genomic location:11q13.3 (C-H) Consequence of DNA analysis: (C) The patient carrying 2201T $>C$ mutation. (D) His father carrying $2201 T>C$ mutation. (E) His mother: normal. (F) The patient carrying 1318T>C mutation. $(G)$ His father: normal. $(H)$ His mother carrying 1318T $>C$ mutation. (I) Multiple species alignment analysis showed the high evolutionary conservation of amino acid sequence at the mutation site. 

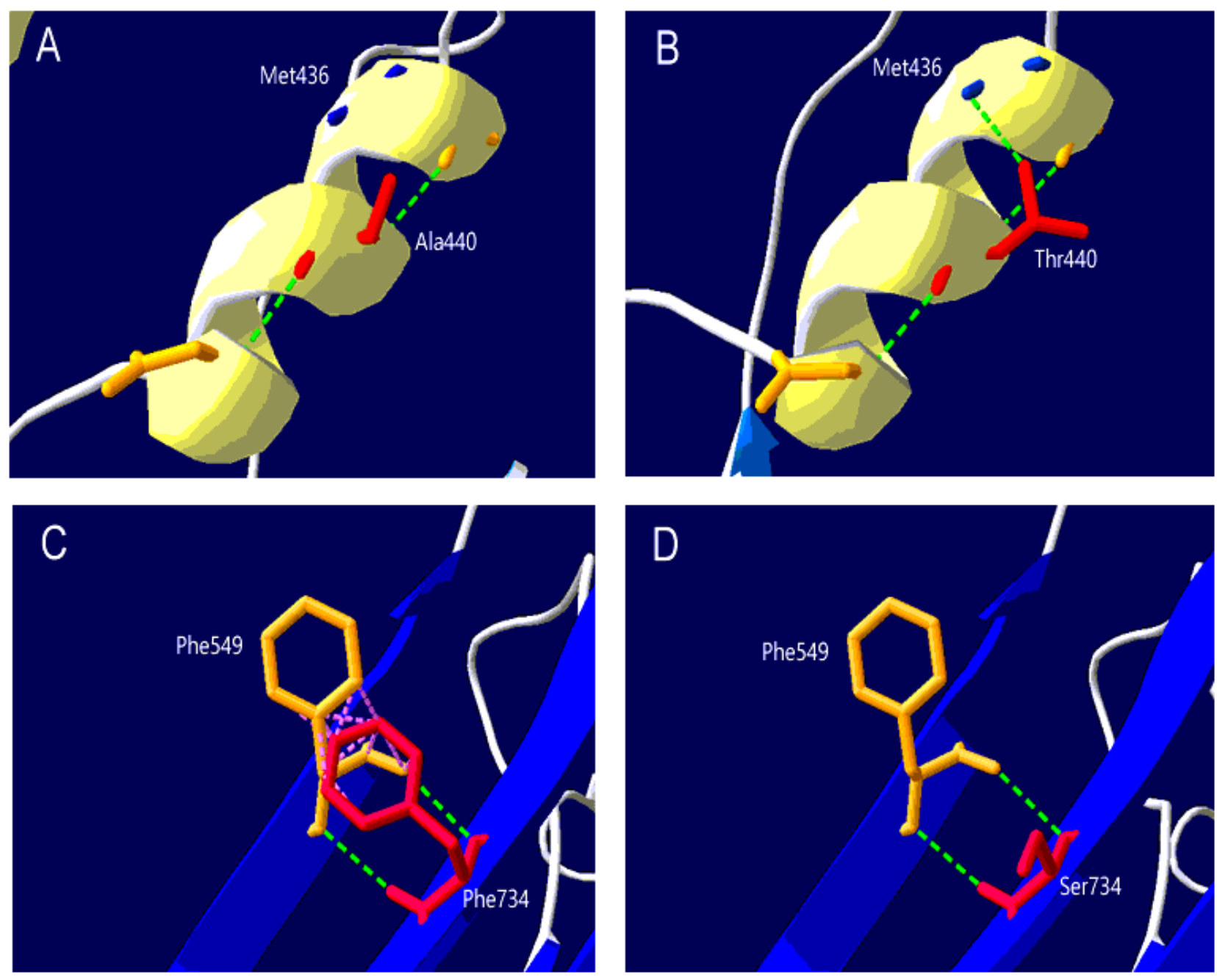

\section{Figure 2}

3-D structure of the wild type and p.A440T/p.F734S CPT1A proteins with prediction software. (A) Before p.A440T mutation. (B) After p.A440T mutation. (C) Before p.F734S mutation. (D) After p.F734S mutation. (The green dotted lines are hydrogen bond, and the red dotted lines are hydrophobic bond.) 

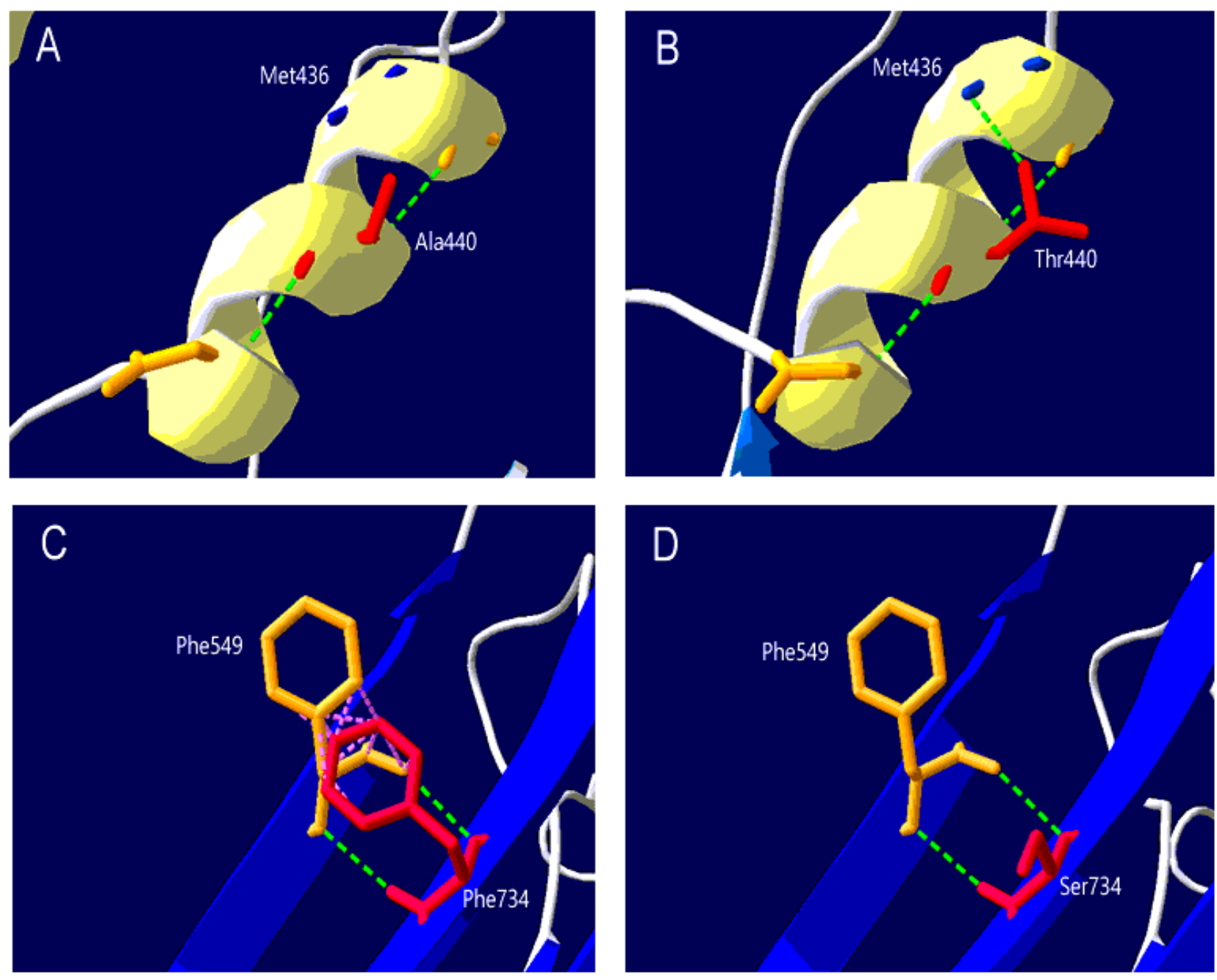

\section{Figure 2}

3-D structure of the wild type and p.A440T/p.F734S CPT1A proteins with prediction software. (A) Before p.A440T mutation. (B) After p.A440T mutation. (C) Before p.F734S mutation. (D) After p.F734S mutation. (The green dotted lines are hydrogen bond, and the red dotted lines are hydrophobic bond.)

\section{Supplementary Files}

This is a list of supplementary files associated with this preprint. Click to download.

- care.jpg

- care.jpg 